\title{
PROBABILISTIC STABILITY ANALYSIS OF LOW FREQUENCY OSCILLATION OF LARGE- SCALE INTERCONNECTED POWER GRID BASED ON THE THEORY OF POINT ESTIMATION METHOD AND RISK ASSESSMENT
}

\author{
Xuan Gong, Feifei Dong, Chao Dong
}

Original scientific paper The indicators and methods of the probabilistic stability analysis of interconnected power grid's low frequency oscillation are put forward in this paper, and the case study based on the real interconnected power grid is investigated. As the probabilistic distribution of various uncertain factors of power grid is known, the method of two-point-estimation is adopted to calculate the probabilities of low-frequency oscillation caused by these uncertain factors based on small perturbation calculation method. The theory of risk assessment is used to analyse the instability condition of power system's low frequency oscillation caused by multiple disturbances, and then the control cost and the risk of low frequency oscillation of power grid are given. The expenses between the risks the power grid companies have taken and the costs the transmission capacity has increased are obtained through comprehensive probability analysis of small disturbance and large disturbance, which can give insights for grid operators to address the economy and security issues.

Keywords: low frequency oscillation; multiple disturbances; point estimation method; probability of stability; risk assessment

\section{Analiza vjerojatnosti stabilnosti oscilacija niske frekvencije na veliko međusobno povezane energetske mreže utemeljena na teoriji metode procjene točke i procjene rizika}

Izvorni znanstveni članak

U radu su prikazani pokazatelji i metode analize vjerojatnosti stabilnosti oscilacija niske frekvencije međusobno povezane energetske rešetke i daje se analiza slučaja temeljena na stvarnoj uzajamno povezanoj energetskoj rešetki. Kako je poznata probabilistička distribucija raznih nesigurnih čimbenika energetske rešetke, koristi se metoda procjene dvije točke (two-point-estimation) u izračunu vjerojatnosti oscilacija niske frekvencije izazvanih tim nesigurnim čimbenicima zasnovana na metodi izračuna malih perturbacija. Teorija procjene rizika koristi se $u$ analizi stanja nestabilnosti niskofrekventnih oscilacija energetskog sustava izazvanih višestrukim smetnjama, a zatim se daju troškovi upravljanja i mogućnost oscilacija niske frekvencije energetske rešetke. Troškovi između rizika koje su preuzele kompanije i povećanih troškova prijenosa dobiveni su opsežnom analizom vjerojatnosti malih smetnji i velikih smetnji, što može potaknuti operatore rešetke da poduzmu ekonomske i sigurnosne mjere.

Ključne riječi: metoda procjene točke; oscilacije niske frekvencije; procjena rizika; višestruke smetnje; vjerojatnost stabilnosti

\section{Introduction}

Low frequency oscillations of interconnected power grid can be detrimental in power system operation since they limit the power capacity of tied line transmission, and may result in making the oscillation of system out of step due to insufficient damping after the failure [1-2]. And this phenomenon in power system has occurred many times in China to date. One common method for the low-frequency oscillation testing is the small signal stability analysis under the certain designed operation mode in traditional power system [1]. The drawback of this method is that it does not consider the random factors such as load fluctuations and power dispatch, and the risk of low frequency oscillation caused by large disturbance. Due to the influence of uncertainties such as the load and structure variation, and variable component parameters, great gaps may exist between the practical operation condition and the typical operation mode, and therefore big errors between the model parameters used for simulation and the actual data of the system are inevitable. Conventional deterministic analysis methods do not include these uncertain factors, therefore, they are difficult to be applied to actual power grid. Besides, previous studies focus on the low frequency oscillation of the actual system that is caused by the single disturbance. However, the true case is that the low frequency oscillations are caused by multiple disturbances, which are not considered in the existing methods analysis [3-4]. Thus, it is necessary to include the stochastic factors and multiple disturbances to estimate the risk of low frequency oscillation of the power grid comprehensively and prevent such oscillation accidents.

Probabilistic stability analysis methods are able to make up the limitations of the deterministic methods which can only estimate the stability in certain operation mode. Therefore, they have broad application prospects in the planning and operation of power system [5-11]. Among the existing methods of small signal stability probabilistic analysis, the Monte Carlo simulation (MCS) is an excellent method to take many kinds of random factors into account, and it is simple and convenient. But it needs a large number of sampling data and recursive operations $[11,12]$. Two point estimation (TPE) method is introduced to obtain statistical characteristics of system with the merits of less computational works and high precisions. The method of risk assessment is the extension of probabilistic method. The economic and safety factors are both emphasized in this method, which embodies the new requirements of power system stability analysis [58]. The method of two-point estimation is used to assess the probability stability of low frequency oscillation in Reference [9-10]. The problem is that these papers assume the ideal condition with the stable probability is 1 , and neglect the impact of large disturbance as well. A comprehensive estimation of the dynamic stability of interconnected power grid is studied in Reference [13], but the small disturbance stability analysis fails to include the influence of random factors. At present, few research works take into account both small disturbance and large disturbance in probabilistic stability analysis. 
Based on the two point estimation method and risk assessment, the indicators and methods of the probabilistic stability analysis of low frequency oscillation are put forward and one case study of practical power grid is given to verify the effectiveness of the proposed method.

\section{Risk assessment of probabilistic stability of low frequency oscillation \\ 2.1 Probabilistic stability analysis of low frequency oscillation under small disturbance}

The linear model of power system can be unified in mathematical description as the following general form,

$$
\left[\begin{array}{c}
\Delta \dot{\boldsymbol{x}} \\
0
\end{array}\right]=\left[\begin{array}{ll}
\boldsymbol{A}_{f 11} & \boldsymbol{A}_{f 12} \\
\boldsymbol{A}_{f 21} & \boldsymbol{A}_{f 22}
\end{array}\right]\left[\begin{array}{l}
\Delta \boldsymbol{x} \\
\Delta \boldsymbol{y}
\end{array}\right]
$$

where $\Delta \boldsymbol{x} \in \boldsymbol{R}^{n}$ are state variables of the system, and $\Delta \boldsymbol{y} \in \boldsymbol{R}^{l}$ are algebraic variables of the system. Eigenvalues, eigenvectors, mechanical and electrical circuit correlation ratio and relevant factors such as the damping ratio related to the characteristic root are obtained by Eq. (1). When the characteristic roots of power grid vary due to disturbances caused by uncertain factors, the real component of eigenvalues must be always in the negative side of complex plane to satisfy the following,

$$
P_{\mathrm{st}}=P\left\{\alpha_{i}<0\right\}=\int_{-\infty}^{0} f\left(\alpha_{i}\right) \mathrm{d} \alpha_{i}=1
$$

where $f\left(\alpha_{i}\right)$ is the probability density function of $\alpha_{i}, P_{\mathrm{st}}$ is stability probability of low frequency oscillation under the condition of small disturbance.

The mean and standard deviation of the real part $\alpha_{i}$ of $\lambda_{i}$ are set as $\bar{\alpha}_{i}$ and $\sigma_{\alpha i}$ respectively. According to the characteristics of normal distribution, $\alpha_{i}$ can be assumed to be located in the area when $\alpha_{i}$ fall in the interval of $\left[\bar{\alpha}_{i}-4 \sigma_{\alpha i}, \bar{\alpha}_{i}+4 \sigma_{\alpha i}\right]$ with the probability of 0,99994 .

In order to ensure the stability of the system, the interval mentioned above should be completely within the left half plane of the complex plane, namely,

$$
\alpha_{i}^{*}=\frac{-\bar{\alpha}_{i}}{\sigma_{\alpha, i}}>4 .
$$

Similarly, if the damping ratio $\xi_{i}$ also satisfies normal distribution with the mean $\bar{\xi}_{i}$ and standard deviation $\sigma_{\xi i}$, the damping ratio needs to satisfy,

$$
\xi_{i}^{*}=\frac{-\bar{\xi}_{i}}{\sigma_{\xi i}}>4
$$

The larger $\alpha_{i}^{*}$ is, the smaller variation of $\alpha_{i}$ will be as the uncertain factors changes. And the stability of power grid will be strong if the corresponding $-\bar{\alpha}_{i}$ is big enough. Similarly, the larger $\xi_{i}^{*}$ is, the smaller variation of $\xi_{i}$ will be when the uncertain factors change. And also if the corresponding $\xi_{i}^{*}$ is larger, the stability of power grid will be stronger. The key issue for risk assessment of low frequency oscillation is to obtain the index based on different distribution features of the uncertain factors. Therefore, two point estimation method is proposed to analyse the probabilistic stability of low frequency oscillation in this paper.

Two point estimation method is the probability statistical method of acquiring the moments of random variable according to the probability distribution of random variables $[9,10]$. The statistical characteristics such as the mean and variance can be obtained with fewer operations by this method. Uncertainty can be represented by the random parameter $x$, and undetermined statistical properties of variables such as the characteristic roots) can be represented by a random variable $y$. Theoretically, the distribution of $y$ can be obtained by the distribution of $x$. If the relationship between them is relatively complex, the distribution of $y$ will become extremely difficult, and needs to rely on the appropriate numerical calculation method.

Define $\boldsymbol{y}$ as $N$ dimensional random function of $\boldsymbol{x}$,

$\boldsymbol{y}=\boldsymbol{h}(\boldsymbol{x})=\boldsymbol{h}\left(x_{1}, \cdots, x_{N}\right)$

where it meets the following relations, $\boldsymbol{x}=\left[x_{1}, x_{2}, \cdots, x_{N}\right]^{\mathrm{T}}$, $\boldsymbol{y}=\left[y_{1}, y_{2}, \cdots, y_{M}\right]^{\mathrm{T}}, \boldsymbol{h}=\left[h_{1}, h_{2}, \cdots, h_{M}\right]^{\mathrm{T}}$.

The mean, standard deviation and the probability density function of $x_{k}$ represent $\bar{x}_{k}, \sigma_{k}$ and $f_{k}$ respectively. The $l^{\text {th }}$ order of central moment $M_{k, l}$ of $x_{k}$ and its coefficient of standard deviation $L_{k, l}$ are defined as the following,

$\left\{\begin{array}{l}M_{k, l}=\int_{-\infty}^{+\infty}\left(x_{k}-\bar{x}_{k}\right)^{l} f_{k}(x) \mathrm{d} x \\ L_{k, l}=\frac{M_{k, l}}{\left(\sigma_{k}\right)^{l}} \quad, l=1,2,3 \cdots, n\end{array}\right.$

where $L_{k, 1}=0, L_{k, 2}=1, L_{k, 3}$ are slope coefficients of $x_{k}$. The estimated value, mean, and standard deviation of the $l^{\text {th }}$ order of $y_{j}$ can be calculated by the following formulas.

$$
\begin{aligned}
E\left(y_{j}^{l}\right)= & \sum_{\substack{k=1\\
}}^{N}\left[p_{k, 1} h_{j}\left(\bar{x}_{1}, \bar{x}_{2}, \cdots, x_{k, 1}, \cdots, \bar{x}_{N}\right)+\right. \\
& \left.p_{k, 2} h_{j}\left(\bar{x}_{1}, \bar{x}_{2}, \cdots, x_{k, 2}, \cdots, \bar{x}_{N}\right)\right]
\end{aligned}
$$

If two values are taken from $x_{k}$, and define it as $x_{k, m}=\bar{x}_{k}+\zeta_{k, m} \sigma_{k}$, and then it will get as follows, 


$$
\begin{aligned}
& \left\{\begin{array}{l}
\zeta_{k, m}=\frac{L_{k, 3}}{2}+(-1)^{3-m} \sqrt{N+\left(\frac{L_{k, 3}}{2}\right)^{2}} \\
p_{k, m}=\frac{\frac{1}{N}(-1)^{m} \zeta_{k, m}}{2 \cdot \sqrt{N+\left(\frac{L_{k, 3}}{2}\right)^{2}}}
\end{array},\right. \\
& \sigma_{z j}=\sqrt{E\left(y_{j}^{2}\right)-\left[E\left(y_{j}\right)\right]^{2}},
\end{aligned}
$$

where $m=1,2 ; k=1, \ldots, N$.

As it can be seen the two point estimation method could get statistical information of the mean and standard deviation value of random variables through less calculation work if the 3rd order of moments of random parameter is known. For problems with $\mathrm{n}$ random parameters, two point estimation method only needs $2 n$ calculation. In practice, $x=\left(P_{\mathrm{L}} Q_{\mathrm{L}} X_{\mathrm{C}} P_{\mathrm{G}} \cdots\right)$ indicates the actual load, power node voltage, and circuit parameters, and $y=\left(\lambda_{i} \alpha_{i} \xi_{i} \cdots\right)$ denotes the undetermined random variables.

\subsection{Risk assessment of low frequency oscillation under large disturbance}

The sensitivity method is applied to form a group of serious failure faults events, and then the failure probability and consequence of these events are estimated under large disturbance.

According to the risk indices of system transient stability in Reference [8], the risk indicator of dynamic stability of low frequency oscillation under large disturbance is defined as follows,

$$
R(K)=\sum_{i=1}^{n} R\left(E_{i}\right)=\sum_{i=1}^{n} P_{r}\left(K \cap T \cap E_{i}\right) I_{m}\left(K \cap T \cap E_{i}\right),
$$

where $P_{r}\left(K \cap T \cap E_{i}\right)$ is the instability probability of low frequency oscillation. $I_{m}\left(K \cap T \cap E_{i}\right)$ denotes the consequences of dynamic instability by control cost, $n$ is the number of the component in the serious fault.

The instability probability of low frequency oscillation of the line $i$ after the failure is as follows,

$$
P_{r}\left(K \cap T \cap E_{i}\right)=P_{r}\left(E_{i}\right) P_{r}(T \mid E) P_{r}\left(K \mid E_{i} \cap T\right),
$$

where $E_{i}$ denotes the system's state when the line $i$ is with a failure, $T$ represents the line trips after the fault, $K$ is the instability of low frequency oscillation of the system.

For AC lines, according to the formula of Poisson distribution, the probability that the line $i$ does not fall into the failure within the given time $t$ is shown as follows,

$P_{r}\left(\bar{F}_{i}\right)=\frac{\left(\lambda_{i} t\right)^{0} \mathrm{e}^{-\lambda_{i} t}}{0 !}=\mathrm{e}^{-\lambda_{i} t}$
The probability that the line $i$ falls into the failure within the given time $t$ is shown as follows,

$$
\begin{aligned}
& P_{r}\left(F_{i}\right)=1-\mathrm{e}^{-\lambda_{i} t}, \\
& P_{r}\left(F_{i}\right)=P_{r}\left(\bar{F}_{1} \cap \cdots \cap \bar{F}_{i-1} \cap \bar{F}_{i} \cap \bar{F}_{i+1} \cap \cdots \bar{F}_{n}\right)=\left(1-\mathrm{e}^{-\lambda_{i} t}\right) \mathrm{e}^{-\sum_{j-1}^{j+\lambda_{j} t}}
\end{aligned}
$$

When it meets the condition of $\sum \lambda_{j} t \rightarrow 1$, there will be,

$$
P_{r}\left(E_{i}\right) \approx P_{r}\left(F_{i}\right),
$$

where $F_{i}$ denotes short-circuit fault of the line $i, \lambda_{i}$ expresses the failure rate of the line $i$ in the given time $t$ (time/per unit time), $T$ is the time interval, $n$ denotes the number of the key lines. For AC lines, assuming that the re-closure of the breaker is set in a mode that re-closure is triggered after single-phase line fault. If the action is not successful, the trip of three-phase lines will be triggered. Besides other types of faults would directly lead to the trip of the three-phase lines.

$$
P\left(T \mid E_{i}\right)=P\left(A=1 \mid E_{i}\right) P\left(T \mid(A=1) \cap E_{i}\right)+P\left(A \neq 1 \mid E_{i}\right) P\left(T \mid(A \neq 1) \cap E_{i}\right)
$$

where $A=1,2,3,4$ indicates the events of single phase short circuit fault, two phase short circuit fault, two phase ground short fault and three-phase short-circuit fault respectively. $P\left(T \mid(A=1) \cap E_{i}\right)$ denotes the probability of the trip of three-phase after the unsuccessful reclosing of single-phase fault. $P\left(T \mid(A \neq 1) \cap E_{i}\right)$ denotes the probability of the three-phase line trip caused by other types of faults, and it meets $P\left(T \mid(A \neq 1) \cap E_{i}\right)=1$. When the event of the unipolar lockout of AC lines happens, it meets $P\left(T \mid E_{i}\right)=1$.

Economical and safety issues are both investigated in Reference [8], and the probability of power off is used to assess the consequences of transient instability. Risk assessment of low frequency oscillation under multiple disturbances is investigated in this paper, and the control cost is used to measure the consequences of instability of low frequency oscillation under large disturbance. The consequences of instability of low frequency oscillation are represented by the control cost as follows,

$$
I_{m}=\left(r_{3}-r_{1}\right) P_{1} t_{1}-\left(r_{3}-r_{2}\right) P_{2} t_{2}+\sum_{i} C_{i} P_{i} t_{i}+I_{m}^{\prime},
$$

where $r_{1}, r_{2}, r_{3}$ are the feed-in tariff of the sending generator, the electricity price of standby generators of the power grid, and the retail price of power grid company respectively. $P_{1} t_{1}$ denotes the cutting load capacity of emergency control, $P_{2} t_{2}$ is the spare capacity of the power grid, $P_{i} t_{i}$ is the cutting of the load capacity $i$, $C_{i}$ is the compensation capacity to cutting of load $i$ in unit by power grid company, $I_{m}^{\prime}$ denotes other expenses, including the start-up fee and maintenance costs of 
backup generator.

\section{Simulation analysis \\ 3.1 Basic structure}

An interconnected power grid is studied in this paper, the structure of which is shown in Fig. 1. The network of voltage level of $220 \mathrm{kV}$ and above is taken into account. The typical operation mode is that the power flow is from power grid $\mathrm{C}$ to power grid $\mathrm{B}$ and then to power grid $\mathrm{A}$. Power grid $\mathrm{B}$ has a number of lines to interconnect the other two grids. L1 to L8 are the links between provinces of the regional power grid. The stability of low frequency oscillation of interconnected power grid is studied under the typical operation mode 1 .

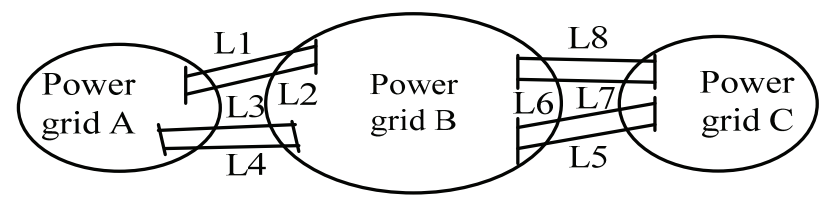

Figure 1 Basic network frame structure of the real region grid

\subsection{Risk assessment of stability under small disturbance based on two point estimation method}

Due to the less computational work of two point estimation method, it is feasible to study the risk assessment of low frequency oscillation of the real system. The impacts of the probabilistic stability of low frequency oscillation of the actual region grid under small disturbance are discussed based on two different uncertain factors modes.

1) Load fluctuation. Since the error between the forecasting result of load and the actual load always exists, so the actual load can be seen as random variable that satisfies the normal distribution. The mean value of the normal distribution is the level of load, and the accuracy of load forecasting determines the value of the standard deviation of normal distribution. Power grid B is selected as a research object, and the level of load is set to obey the skew normal distribution with its predictive value that satisfied $5 \%$ standard deviation and slope value of 0,006 .

2) Variation of circuit parameters of interconnected lines between regional areas. The lines between provinces of power grid A and power grid B, L1 and L2, and are installed the series compensation device. Assume that its compensation obeys the normal distribution of $X_{C}=N\left(\bar{X}_{C}, 20 \%\right)$.

When two point estimation method is applied to calculate the probability of stability, random parameters $x_{k, m}(m=1,2 ; k=1,2)$ should firstly be calculated according to the statistical features of load fluctuation and circuit parameters. And then characteristics of the root are obtained. At last, the stable probability is given. Specific steps are given as follows: the slope coefficient of each uncertainty is calculated by Eq. (6), weighting factor $\zeta_{k, m}$ and parameters $p_{k, m}$ are calculated by Eq. (8), and then four random parameters $x_{k, m}$ can be obtained by $x_{k, m}=\bar{x}_{k}+\zeta_{k, m} \sigma_{k}$. The characteristic roots of the system are calculated with four random parameters respectively. Finally, the mean and standard deviation of the system under the two kinds of uncertainty factors are calculated through Eq. (7) to Eq. (9). The corresponding stability probability and stability index are calculated by Eq. (2) to Eq. (4), and its result is shown in Tab. 1. Due to a large number of cases, only the modes of low frequency oscillation with smaller indicator are given.

Table 1 The probabilistic stability analysis of low frequency oscillation under operation mode 1

\begin{tabular}{|c|c|c|c|c|c|c|c|c|}
\hline Mode & $\begin{array}{c}\text { Real } \\
\text { part }\end{array}$ & $\begin{array}{c}\text { Image } \\
\text { part }\end{array}$ & $\begin{array}{c}\text { Frequency / } \\
\mathrm{Hz}\end{array}$ & $\begin{array}{l}\text { Damping } \\
\text { ratio / \% }\end{array}$ & $\begin{array}{l}\text { Mechanical and } \\
\text { electrical circuit } \\
\text { correlation ratio }\end{array}$ & $\begin{array}{c}\text { Stability } \\
\text { probability } P_{\alpha 0}\end{array}$ & $\begin{array}{c}\text { Characteristic root } \\
\text { indicators } \alpha_{i}^{*}\end{array}$ & $\begin{array}{l}\text { Damping ratio } \\
\text { indicators } \xi_{i}^{*}\end{array}$ \\
\hline 1 & $-0,68$ & 10,68 & 1,70 & 6,36 & 6,06 & 1,0 & 8,46 & 8,57 \\
\hline 2 & $-0,57$ & 10,63 & 1,69 & 5,32 & 3,22 & 1,0 & 13,48 & 12,87 \\
\hline 3 & $-0,64$ & 8,82 & 1,40 & 7,22 & 6,04 & 1,0 & 10,98 & 10,96 \\
\hline 4 & $-0,65$ & 8,79 & 1,39 & 7,42 & 5,97 & 1,0 & 7,57 & 7,77 \\
\hline 5 & $-0,36$ & 6,67 & 1,06 & 5,41 & 13,71 & 1,0 & 6,43 & 6,35 \\
\hline 6 & $-0,22$ & 2,69 & 0,43 & 8,25 & 0,65 & 0,9966 & 2,93 & 2,89 \\
\hline
\end{tabular}

Table 2 The probabilistic stability analysis of low frequency oscillation under operation mode 2

\begin{tabular}{|c|c|c|c|c|c|c|c|c|}
\hline Mode & $\begin{array}{l}\text { Real } \\
\text { part }\end{array}$ & $\begin{array}{l}\text { Image } \\
\text { part }\end{array}$ & $\begin{array}{c}\text { Frequency } \\
/ \\
\mathrm{Hz}\end{array}$ & $\begin{array}{l}\text { Damping } \\
\text { ratio / \% }\end{array}$ & $\begin{array}{l}\text { Mechanical and } \\
\text { electrical circuit } \\
\text { correlation ratio }\end{array}$ & $\begin{array}{c}\text { Stability } \\
\text { probability } P_{\alpha 0}\end{array}$ & $\begin{array}{c}\text { Characteristic root } \\
\text { indicators } \alpha_{i}^{*}\end{array}$ & $\begin{array}{l}\text { Damping ratio } \\
\text { indicators } \xi_{i}^{*}\end{array}$ \\
\hline 1 & $-0,44$ & 10,72 & 1,70 & 4,07 & 7,50 & 1,0 & $+\infty$ & $+\infty$ \\
\hline 2 & $-0,74$ & 10,66 & 1,69 & 6,90 & 9,71 & 1,0 & 1702942,43 & $+\infty$ \\
\hline 3 & $-0,54$ & 8,81 & 1,40 & 6,07 & 16,45 & 1,0 & 1584,99 & 93,11 \\
\hline 4 & $-0,58$ & 8,76 & 1,39 & 6,64 & 14,06 & 1,0 & 2285,72 & 117,51 \\
\hline 5 & $-0,59$ & 6,78 & 1,08 & 8,72 & 3,43 & 1,0 & 6295,05 & 579,63 \\
\hline 6 & $-0,27$ & 2,90 & 0,46 & 31,61 & 0,64 & 1,0 & 92,10 & 453,52 \\
\hline
\end{tabular}

As it can be seen in Tab. 1 the overall load fluctuation of power grid B is within $5 \%$. When the series compensation of two-loop, L1 and L2, between Power grid A and Power grid B obeys normal distribution of $X_{C}=N\left(\bar{X}_{C}, 20 \%\right)$, it can be harmful to the stability of the system. The probabilistic stability of low frequency oscillation under operation mode 6 is around 0,9966 according to the normal distribution table. The system is 
approximately stable, but its stability margin is relatively smaller than others.

On the basis of operation mode 1 , operation mode 2 is set as the scenario when the power flow of Area $\mathrm{C}$ to Area A is reduced by $505 \mathrm{MW}$. The results of small signal stability assessment with the application of two point estimation method are shown in Tab. 2.

Under the operation mode 2, the probability stability of the model 6 is improved. It is concluded that the reduced output power flow to Area C is helpful to improve the probability stability of low frequency oscillation of power grid. Therefore, in system planning, it is reasonable to adjust the power grid operation mode and circuit parameters according to the actual statistical data, to improve the probability of low frequency oscillation stability. And the other condition that needs to be monitored carefully is the operation mode of intensiverelated units with lower probability stability of low frequency oscillations.

\subsection{Risk assessment of stability under large disturbance based on multiple large disturbances}

Sensitivity analysis method is used to form a serious fault set to analyse the consequences of component failure. Since there are many vulnerable linked lines, only parts of lines included in the serious fault set are listed. SZ, SX, ZJ are the lines with high voltage and heavy load in Area $\mathrm{C}$ of power grid, events with multiple disturbances are set up to trigger low frequency oscillation, and it leads to the instability of the system. Two kinds of disturbances sequences are shown in Tab. 3 .

Table 3 Settings of multiple disturbances sequences

\begin{tabular}{|c|c|c|c|c|}
\hline \multirow{2}{*}{$\begin{array}{c}\text { Multiple } \\
\text { Disturbances }\end{array}$} & \multicolumn{2}{|c|}{ Disturbed sequence 1} & \multicolumn{2}{|c|}{ Disturbed sequence 2} \\
\hline & First disturbance & Double disturbances & First disturbance & Double disturbances \\
\hline Type & $\begin{array}{l}\text { Three phase short } \\
\text { circuit }\end{array}$ & $\begin{array}{c}\text { Trip after three } \\
\text { phase short circuit }\end{array}$ & $\begin{array}{c}\text { Trip after three } \\
\text { phase short circuit }\end{array}$ & $\begin{array}{c}\text { Trip after three phase } \\
\text { shortcircuit }\end{array}$ \\
\hline Place & $\mathrm{SZ}$ & $\mathrm{SX}$ & $\mathrm{SZ}$ & \begin{tabular}{c|c} 
& $\mathrm{ZJ}$ \\
\end{tabular} \\
\hline time/s & $1 \div 1,1$ & $6 \div 50$ & $1 \div 50$ & $6 \div 50$ \\
\hline
\end{tabular}

$r_{1}, r_{2}, r_{3}$ are set as $300 \mathrm{CNY} / \mathrm{MW} \cdot \mathrm{h}, 450 \mathrm{CNY} /$ $\mathrm{MW} \cdot \mathrm{h}, 500 \mathrm{CNY} / \mathrm{MW} \cdot \mathrm{h}$ respectively, and $C_{i}$ are all set as $2000 \mathrm{CNY} / \mathrm{MW} \cdot \mathrm{h}$ [13]. There are $1270 \mathrm{MW}$ spinning reserve capacity of pumped hydraulic storage in the receiving point of Power grid $\mathrm{B}$. The standby generators can restore partial loads. Assume the duration of power output is $6 \mathrm{~h}$, and the start-up time of backup generators is $0,4 \mathrm{~h}$.

The failure rate of $\mathrm{AC}$ lines is 0,001115 times daily. The probability of different types of faults is shown in Tab. 4 [8].The success rate of breaker reclosing of short circuit can reach $60 \div 90 \%$ [14]. The successful probability of the reclosing of three phase fault reaches 84 $\%$.

Table 4 Probability statistics of short-circuit faults of AC lines

\begin{tabular}{|l|c|}
\hline \multicolumn{1}{|c|}{ Type } & Probability /\% \\
\hline Three phase short circuit & 6,2 \\
\hline Two phase ground short & 10 \\
\hline Single phase ground short & 75 \\
\hline Two phase interphase short circuit & 8,8 \\
\hline
\end{tabular}

Given the sets of the disturbance sequence 1 and disturbance sequence 2 , serious unstable oscillations are observed after double disturbances. The power flow curves of linked line, L7, which is between provinces B and $\mathrm{C}$ are shown in Fig. 2 and Fig. 3 respectively.

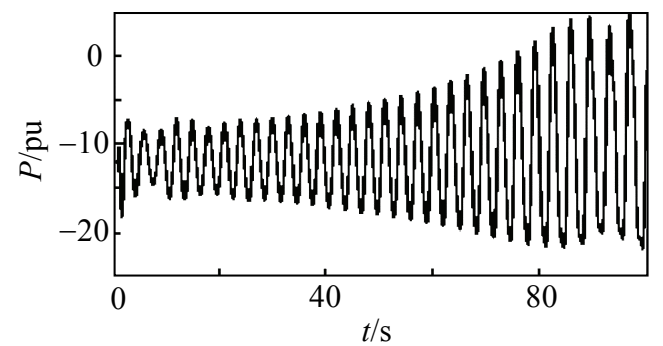

Figure 2 Transmission power of L7 under multiple disturbances sequence 1

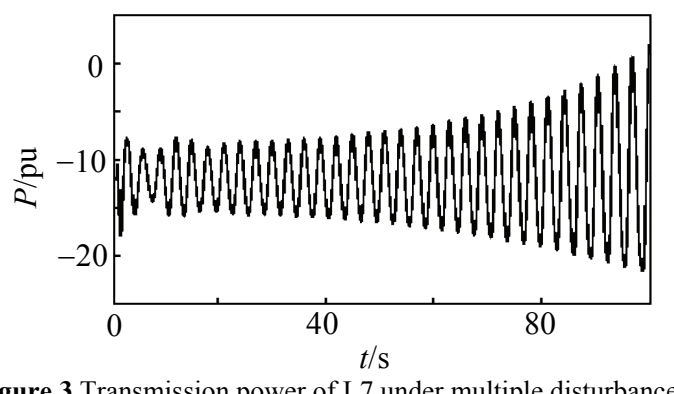

Figure 3 Transmission power of L7 under multiple disturbances sequence 2

If the output power of Area $\mathrm{C}$ to Area $\mathrm{A}$ is reduced by $505 \mathrm{MW}$, and the load of Area A is cut by $450 \mathrm{MW}$, the oscillation of system would quickly be damping out under the same sequence of multiple disturbances. The control cost and risk of low frequency oscillation corresponding to different disturbance sequences are shown in Tab. 5.

Table 5 The control cost and risk of low frequency oscillation under different multiple disturbance sequences

\begin{tabular}{|c|c|c|}
\hline $\begin{array}{c}\text { Multiple disturbance } \\
\text { sequences }\end{array}$ & $\begin{array}{c}\text { Control cost / } \\
\text { CNY }\end{array}$ & $\begin{array}{c}\text { Dynamic stability } \\
\text { risk / CNY }\end{array}$ \\
\hline 1 & 1070600 & 0,295 \\
\hline 2 & 1070600 & 0,182 \\
\hline
\end{tabular}

The probability of multiple disturbances in real operation in power grid is low. Among the serious fault sets, single fault disturbance of important lines is only with the probability of 0,000367 that the lines trip after short circuit), but the control cost of reducing output power delivery and the load shedding may cause millions of money without adding other additional cost. However, similar accidents of low frequency oscillation under multiple disturbances often occur in power grid, such as "8.10" incident of north American WECC grid in 1996, "7.1" incident of central China power grid, and 6.17B switch factory explosion accidents in Jinzushan, Hunan, 
et al. $[15,16]$. Therefore, the operation condition of important lines should be monitored actively in the case of heavy flow of interconnected lines between regional areas, and thus low frequency oscillation can be detected in time and avoid large economic losses brought by oscillation of power grid.

\section{Conclusion}

(1) A probabilistic stability analysis method of interconnected power grid's low frequency oscillation based on two point estimation method is put forward by considering the uncertainty factors in the real system. The stability of low frequency oscillation of the system can be enhanced by altering system's operation mode reasonably.

(2) The incidents of low frequency oscillation of power grid under multiple disturbances are analysed based on the theory of risk assessment. The incidence of multiple disturbances is low, but the control cost of low frequency oscillation is very expensive once that it occurs. Therefore, the operation condition of important lines needs to be monitored actively, and give alert of low frequency oscillation.

(3) The probabilistic stability of interconnected power grid's low frequency oscillation under small disturbance and multiple disturbances is comprehensively evaluated by two point estimation method and risk assessment is analysed as well. There are numerous factors that would trigger low frequency oscillation in the real power grid. Comprehensive risk assessment system should be established, and probability analysis needs to be performed with the different conditions between the grids.

\section{Acknowledgments}

This work is funded by Dr. Start-up funding of scientific research project of Anhui University (J10113190020).

\section{References}

[1] De, Kun. Power system stability and control. // Beijing, China electric power press, 2002. pp.762-782

[2] Zhu, Fang; Zhao, Hongguang; Liu, Zenghuang et al. The influence of large power grid interconnected on power system dynamic stability. // Proceedings of the CSEE. 27, 1 (2007), pp. 1-7.

[3] Dong, Mingqi; Yang, Dongjun; Huang, Yong et al. Simulation of regional low frequency oscillation based on data measured by WAMS of Central China Power Grid. // Power System Technology. 33, 13(2009), pp. 64-69.

[4] Dang, Jie; Li, Yong; Xu, Youping et al. Power grid low frequency oscillation simulation analysis based on WAMS and singular entropy matrix pencil method. // Automation of Electric Power Systems, 34,12(2010), pp. 14-18

[5] McCalley, J. D.; Vittal, V.; Abi-Samra, N. An overview of risk based security assessment. // Proceedings of IEEE Power Engineering Society Summer Meeting, Edmonton, Canada: IEEE, 1999, pp. 173-178. DOI: 10.1109/pess.1999.784342

[6] Li, W. Y. Risk assessment of power system: model, methods, and applications. // New York, NY, USA: John Wiley \& Sons, 2005, pp. 15-40.
[7] McCalley, J. D.; Fouad, A. A.; Vittal, V. et al. A risk-based security index for determining operating limits in stabilitylimited electric power system. // IEEE Trans on Power Systems. 12, 3(1997), pp. 1210-1219. DOI: 10.1109/59.630463

[8] Vittal, V.; McCalley, J. D.; Van Acker, V. et al. Transient instability risk assessment. // Proceedings of IEEE Power Engineering Society Summer Meeting, Edmonton, Canada: IEEE, 1999, pp. 206-211. DOI: 10.1109/pess.1999.784347

[9] Yi, Haiqiong; Cheng, Shijie; Hou, Yunhe et al. An efficient point estimate method for probabilistic small signal stability analysis. // Automation of Electric Power Systems. 31, 23(2007), pp. 1-4.

[10] Yang, Huimin; Yi, Haiqiong; Wen, Jingyu et al. A practical stability analysis method for large-scale power system based on low frequency oscillation probability. // Transactions of China Electrotechnical Society. 25, 3(2010), pp. 124-129.

[11] Wu, Hong; Zhao, Xia; Zhou, Jiaqi. Monte Carlo simulation of probabilistic small disturbance stability. // Automation of Electric Power Systems. 33, 11(2009), pp. 8-12.

[12] Li, Wenyuan; Lu, Jiping. Monte Carlo method for probabilistic transient stability assessment. // Proceedings of the CSEE. 25, 10(2005), pp. 18-23.

[13] Zhao, Shanshan; Zhou, Ziguan; Zhang, Dongxia et al. Risk assessment index of dynamic stability for large-scale interconnected grids and its application. // Power System Technology. 33, 2(2009), pp. 68-72.

[14] Chen, Cixuan. Electrical engineering foundation. // Beijing, China Electric Power Press, 2004, pp. 91-298.

[15] Xiang, Nong. Research on mechanism and control of interregional low frequency oscillation. //Wuhan: Wuhan University, 2009.

[16] Liao, Qingfen. Research on low frequency oscillation of UHV inter-district grid under multiple disturbances. // Wuhan: Wuhan University, 2008.

\section{Authors' addresses}

Xuan Gong, corresponding author

School of Electrical Engineering, Anhui University, Hefei 232001, Anhui Province, China

E-mail: gongxuan19831117@163.com

\section{Feifei Dong}

School of Electrical Engineering, Wuhan University, Wuhan 430072, Hubei Province, China E-mail: flysky007dong@163.com

\section{Chao Dong}

Guangdong Power Dispatch Center, Guangzhou 510600, Guangdong Province, China E-mail: 597018056@qq.com. 